\title{
A low-cost density reference phantom for computed tomography
}

\author{
Zachary H. Levine ${ }^{\text {a) }}$ \\ Photon Physics Group, National Institute for Standards and Technology, Gaithersburg, \\ Maryland 20899-8410 \\ Mingdong Li \\ Institute for Physical Science and Technology, University of Maryland, College Park, Maryland 20742 \\ Anthony P. Reeves \\ Department of Electrical and Computer Engineering, Cornell University, Ithaca, New York 14853 \\ David F. Yankelevitz \\ Weill Medical College, Cornell University, New York, New York 10065 \\ Joseph J. Chen and Eliot L. Siegel \\ Department of Radiology, University of Maryland Medical Center, Baltimore, Maryland 21201-1595 \\ Adele Peskin \\ Mathematical and Computational Science Division, National Institute for Standards and Technology, \\ Boulder, Colorado 80305-3328 \\ Diana N. Zeiger \\ Polymers Division, National Institute for Standards and Technology, Gaithersburg, Maryland 20899-8453
}

(Received 28 August 2008; revised 17 October 2008; accepted for publication 24 November 2008; published 7 January 2009)

The authors characterized a commercially available foam composed of polyurethane and polyisocyanurate which is marketed for modeling parts in the aircraft, automotive, and related industries. The authors found that the foam may be suitable for use as a density reference standard in the range below -400 Hounsfield units. This range is coincident with the density of lung tissue. The foam may be helpful in making the diagnosis of lung disease more systematic. (C) 2009 American Association of Physicists in Medicine. [DOI: 10.1118/1.3049596]

Key words: lung CT, lung computed tomography, foam phantom, radio density phantom

\section{INTRODUCTION}

The radio densities of tissues as reported by CT machines show uncertainties which may have clinical significance for the diagnosis of lung disease. A machine-to-machine variability of $5 \%$ has been reported ${ }^{1}$ and the effect of reconstruction algorithm was shown to have a variability of up to $9.4 \%$ in the radio density of emphysema. ${ }^{2}$ One approach to reduce the variability is to image reference materials in every scan.

There has been considerable effort to create materials which match the radio density of human tissue, including lung tissue, over several decades. ${ }^{3-5}$ Typically, a complex, synthetic material is derived which is suitable for use in a wide range of exposure conditions. While very suitable for a range of purposes, such materials may be too scarce or costly for widespread use in medical CT imaging. As CT scanners become more widely deployed, they replace the traditional $\mathrm{x}$ ray as a primary diagnostic tool in the workup of lung diseases as well as for continued monitoring. CT imaging has been used to diagnose several diseases of the lungs including cancer, tuberculosis, cystic fibrosis, pneumonia, mesothelioma, chronic obstructive pulmonary disease (COPD), overdistension, asthma, and emphysema. In general, diseases which involve air trapping or increases in lung density can be quantified by this technique. Asthma and emphysema are two examples of dysfunction in air trapping. For increases in lung density, there are certain types of interstitial infections and interstitial edema. We can use these types of calibration devices to track progression or improvement. Many diseases ranging from allergic reactions to drug reactions, inhalation injury, and infection can cause changes in lung density, and it would be possible to more accurately describe whether these change over time.

In a series of papers aimed at making a density standard for lung tissue, Kemerink et al. ${ }^{6-8}$ studied commercially available polyethene foam with densities of $37-186 \mathrm{~kg} / \mathrm{m}^{3}$, corresponding to a range of -965 to $-825 \mathrm{HU}$, and found that by using sample volumes on the order of $50 \mathrm{~mm}^{3}$, it was possible to obtain a density standard with a standard deviation of 3-6 HU depending on the machine Here, HU stands for Hounsfield units. ${ }^{9}$ Their material overlaps the lower end of the range of radio densities required for lung diseases. For example, in the case of emphysema, $-960 \mathrm{HU}$ has been used as a cutoff for diseased areas. ${ }^{10,11}$ However, in a study of lung overdistension a range of values from $-912 \mathrm{HU}$ to just over $-300 \mathrm{HU}$ was reported, ${ }^{12}$ whereas in a study of lung nodules a median value of $38 \mathrm{HU}$ was reported..$^{13}$ Of course, the reported radio density of lung tissue depends on the state of inspiration; this effect can exceed 100 HU. ${ }^{14}$

In this technical note, we report similar results on a commercially available ${ }^{1}$ composite foam based on polyurethane, which is commonly used for floatation devices and packing materials, and polyisocyanate, which is commonly used for 


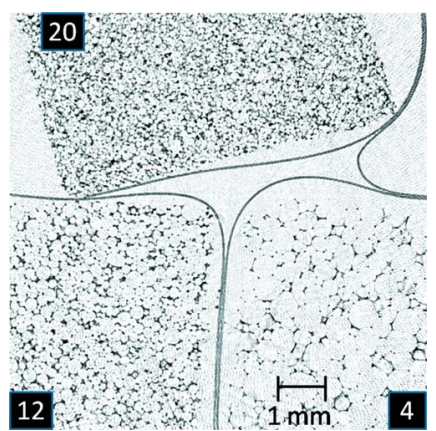

FIG. 1. Micro-CT images of foam samples with nominal densities of 4, 12, and $20 \mathrm{lb} / \mathrm{ft}^{3}$, which correspond to 66,181 , and $303 \mathrm{~kg} / \mathrm{m}^{3}$, acquired by Micro Photonics, Inc. using a SkyScan 1172. The voxel size is $0.0124 \mathrm{~mm}$ per side. The samples are separated by cellophane tape which is visible in the image. The size of the bubbles is larger in the less dense foams.

building insulation. The available density range is somewhat different, namely, $66-656 \mathrm{~kg} / \mathrm{m}^{3}$. Whereas the polyethene used earlier had a density below that of the majority of lung tissue,${ }^{10}$ this will be much less of an issue with the higher density foam studied in this work. The product is typically used by manufacturers to model aircraft or automotive parts and will be called "modeling foam" in this paper. We consider this material to be of "low cost" in the sense that it is sold in individual sheets of $48 \times 96 \times 0.75$ in. $^{3}(1.22 \mathrm{~m}$ $\times 2.44 \mathrm{~m} \times 19 \mathrm{~mm}$ ) for hundreds of U.S. dollars per sheet. An individual sheet would provide enough material for hundreds of individual phantoms. In practice the costs of characterizing the materials would be greater than the cost of the material itself.

\section{MEASUREMENTS}

The materials used were eight samples of the modeling foam with densities stated by the manufacturer to be $4,6,8$, $10,12,15,18$, and $20 \mathrm{lb} / \mathrm{ft}^{3}$, which correspond to 66,109 , $124,154,181,250,285$, and $303 \mathrm{~kg} / \mathrm{m}^{3}$. (Foams with nominal densities of 30 and $40 \mathrm{lb} / \mathrm{ft}^{3}$ are also sold, which correspond to densities of 480 and $640 \mathrm{~kg} / \mathrm{m}^{3}$, respectively.) We had small portions $\left(8 \times 8 \times 19 \mathrm{~mm}^{3}\right)$ of three of the samples examined by micro-CT specifically using a SkyScan 1172 . The sample was reconstructed with cubic voxels $0.0124 \mathrm{~mm}$ on a side. In this experiment, the x-ray tube voltage was 40 $\mathrm{kV}$ and the current was $0.25 \mathrm{~mA}$. A typical slice from the reconstructed image is shown in Fig. 1. The size of the bubbles is larger in the less dense foams. The denser foams have smaller bubbles, but even the least dense foam in this study has bubbles comparable in size to medical CT pixels.

We measured the densities. Since the samples were rectilinear blocks roughly $203 \times 127 \times 19 \mathrm{~mm}^{3}$, we obtained the density from the weight, as measured on a scale, divided by the volume, found as the product of the length, width, and thickness as measured by a caliper. The radio density was also obtained from a Siemens Sensation 64 CT scanner using an x-ray tube voltage of $120 \mathrm{kV}$ and a current of $84 \mathrm{~mA}$. All of the samples were scanned at the same time to ensure uniform exposure conditions. The helical CT scans were per-

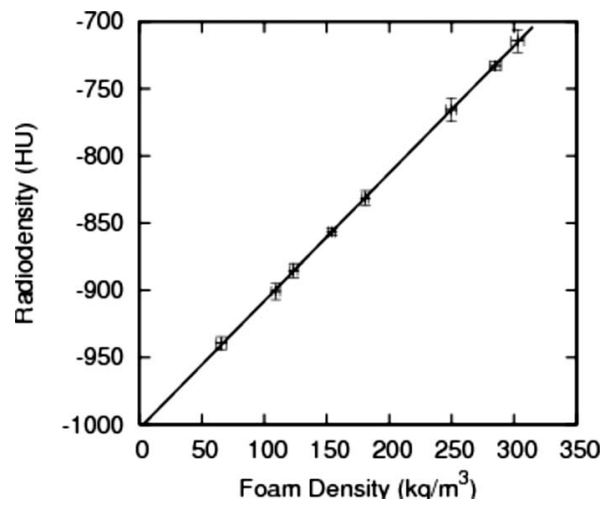

FIG. 2. The radio density of eight foams as a function of the measured density (crossed error bars) and the nominal density (solid circles). The indicated uncertainties are shown at three times the $95 \%$ confidence intervals considering total uncertainties for the density and statistical uncertainties for the radio density. (The symbols are shown at an enlarged size to make them a reasonable size.) The total uncertainty in the density with $95 \%$ confidence is $2 \mathrm{~kg} / \mathrm{m}^{3}$.

formed using a $0.75 \mathrm{~mm}$ slice thickness and a duration of $500 \mathrm{~s}$. The data were reconstructed with the proprietary software SYNGO CT 2006A using the "abdomen-pelvis" protocol.

The radio density is shown in Fig. 2 as a function of the measured density as well as the nominal density. The uncertainty in the radio density was obtained by considering 12 cubes of $13 \times 13 \times 13$ voxels each, chosen from the interiors of each sample. Each voxel is $0.77 \times 0.77 \times 0.75 \mathrm{~mm}^{3}$. The spatial resolution is about $1 \mathrm{~mm}$. For the mean, all the data were averaged. For the standard deviation of the mean, the standard deviation of the means of each of the 12 cubes was chosen. (Short-range correlations prevent the use of the standard formula that the standard deviation of the mean is the standard deviation divided by the number of observation points. We find that the standard formula underestimates the fluctuations by an amount suggesting that cubes of $3 \times 3$ $\times 3$ voxels are the smallest size to be considered statistically independent.) The best fit line to the radio density versus measured density has a slope of $(0.95 \pm 0.01) \mathrm{HU} /\left(\mathrm{kg} / \mathrm{m}^{3}\right)$ and an intercept of $(-1003 \pm 5) \mathrm{HU}$, with the uncertainties at $95 \%$ confidence intervals. The linear fit is excellent as it is within all of the individual uncertainties of the data. A slope just under unity is typical for a polymer, and the intercept is

TABLE I. The densities of the foam as designated by the manufacturer (nominal) and as measured.

\begin{tabular}{ccc}
\hline \hline $\begin{array}{c}\text { Nominal density } \\
\left(\mathrm{lb} / \mathrm{ft}^{3}\right)\end{array}$ & $\begin{array}{c}\text { Nominal density } \\
\left(\mathrm{kg} / \mathrm{m}^{3}\right)\end{array}$ & $\begin{array}{c}\text { Measured density } \\
\left(\mathrm{kg} / \mathrm{m}^{3}\right)\end{array}$ \\
\hline 4 & 64 & 66 \\
6 & 96 & 109 \\
8 & 128 & 124 \\
10 & 160 & 154 \\
12 & 192 & 181 \\
15 & 240 & 250 \\
18 & 288 & 285 \\
20 & 320 & 303 \\
\hline \hline
\end{tabular}


consistent with the defined value ${ }^{1}$ of $-1000 \mathrm{HU}$. For reference, we show the relation of the measured densities to the nominal densities in Table I. Given our uncertainties, $5 \mathrm{HU}$ may be distinguished with $95 \%$ confidence using our sample volume of $20 \mathrm{~cm}^{3}$ by using the data presented in Fig. 2. Similar results were presented earlier by Kemerink et al. for polyethene foams ${ }^{10,12}$ over an overlapping but lower density range.

\section{CONCLUSIONS}

A commercially available polymer foam may be used as a density reference standard in a density range which includes the lung tissue. While the concept of using a polymer foam for this purpose was studied earlier by Kemerink et al., ${ }^{10,12}$ here we have shown that a different material is also suitable, used micro-CT to estimate the bubble sizes, shown that the density range may be extended, and demonstrated a high degree of linearity between density and radio density.

Although we studied rectilinear blocks of foam, because the foam was designed to be machined to simulate industrial parts, it could be machined into biomimetic shapes for use in complex phantoms.

\section{ACKNOWLEDGMENTS}

The authors are pleased to acknowledge helpful discussions, support, and encouragement from Ramalingam Chellappa, Nancy Chen, Charles Clark, Steven Grantham, Karen Kafadar, and Lisa Karam in performing this work. The authors thank Edward Hagley and Bruce Norman for technical assistance. The authors thank Jon Flint for supplying the samples. This work was supported by the NIST Grant No. 70NANB4H1120 (M.L.), NIH/NCI Grant No. R33CA101110-4 (A.P.R.), NIH Grant No. R01-CA-078905 (D.F.Y.), and congressional appropriations. The micro-CT work presented in this paper was performed under contract by Micro Photonics, Inc.

\footnotetext{
${ }^{a)}$ Present address: 100 Bureau Dr., NIST, Gaithersburg, MD 20899-8410, Tel.: 301-975-5453, Fax: 301-208-6937. Author to whom correspondence should be addressed. Electronic mail: zlevine@nist.gov

${ }^{1}$ The product LAST-A-FOAM is manufactured by The General Plastics Corporation. See http://www.generalplastics.com $>$ products (on a tab) $>$
}

FR-7100 Modeling Foam. Commercial products or services are not recommended or endorsed by the authors or their institutions. They may not be the best available for the purpose.

${ }^{1}$ M. Mishima, T. Hirai, Z. Jin, Y. Oku, N. Sakai, Y. Nakano, H. Sakai, K. Chin, M. Ohi, K. Kawakami, K. Shimada, H. Itoh, K. Yamaguchi, T. Sawa, and K. Kuno, "Standardization of low attenuation area versus total lung area in chest X-ray CT as an indicator of chronic pulmonary emphysema," Front Med. Biol. Eng. 8, 79-86 (1997).

${ }^{2}$ K. L. Boedeker, M. F. McNitt-Gray, S. R. Rogers, D. A. Truong, S. Matthew, D. Brown, D. W. Gjertson, and J. G. Goldin, "Emphysema: Effect of reconstruction algorithm on CT imaging measures," Radiology 232, 295-301 (2004).

${ }^{3}$ D. R. White, C. Constantinou, and R. J. Martin, "Foamed epoxy resinbased lung substitutes," Br. J. Radiol. 59, 787-790 (1986).

${ }^{4}$ A. K. Jones, D. E. Hintenlang, and W. E. Boloch, "Tissue-equivalent materials for construction of tomographic dosimetry phantoms in pediatric radiology," Med. Phys. 30, 2072-2081 (2003).

${ }^{5}$ S. Kinase, M. Kimura, H. Noguchi, and S. Yokoyama, "Development of lung and soft tissue substitutes for photons," Radiat. Prot. Dosim. 115, 284-288 (2005).

${ }^{6}$ G. J. Kemerink, R. J. S. Lamers, R. P. Thelissen, and J. M. A. van Engelshoven, "CT densitometry of the lungs: Scanner performance," J. Comput. Assist. Tomogr. 20, 24-33 (1996).

${ }^{7}$ G. J. Kemerink, H. H. Kruize, R. J. S. Larners, and J. M. A. van Engelshoven, "Density resolution in quantitative computed tomography of foam and lung," Med. Phys. 23, 1697-1708 (1996).

${ }^{8}$ G. J. Kemerink, H. H. Kruize, and R. J. S. Larners, "The CT's sample volume as an approximate, instrumental measure for density resolution in densitometry of the lung," Med. Phys. 24, 1615-1620 (1997).

${ }^{9}$ G. N. Hounsfield, "Computed medical imaging," Med. Phys. 7, 283-290 (1980).

${ }^{10}$ N. Sakai, M. Mishima, K. Nishimura, H. Itoh, and K. Kuno, "An automated method to assess the distribution of low attenuation areas on chest CT scans in chronic pulmonary emphysema patients," Chest 106, 13191325 (1994).

${ }^{11}$ H. Koyama, K. Nishimura, A. Ikeda, N. Sakai, M. Mishima, and T. Izumi, "Influence of baseline airway calibre and pulmonary emphysema on bronchial responsiveness in patients with chronic obstructive pulmonary disease," Respir. Med. 90, 323-328 (1996).

${ }^{12}$ S. R. R. Viera, L. Puybasset, J. Richecour, Q. Lu, P. Cluzel, P. B. Gusman, P. Coriat, and J.-J. Rouby, "A lung computed tomographic assessment of positive end-expiratory pressure-induced lung overdistension," Am. J. Respir. Crit. Care Med. 158, 1571-1577 (1998).

${ }^{13}$ S. J. Swensen, R. W. Viggiano, D. E. Midthun, N. L. Müller, A. Sherrick, K. Yamashita, D. P. Naidich, E. F. Patz, T. E. Hartman, J. R. Muhm, and A. L. Weaver, "Lung nodule enhancement at CT: Multicenter study," Radiology 214, 73-80 (2000).

${ }^{14}$ S. R. R. Vieira, L. Puybasset, Q. Lu, J. Richecoeur, P. Cluzel, P. Coriat, and J.-J. Rouby, "A scanographic assessment of pulmonary morphology in acute lung injury," Am. J. Respir. Crit. Care Med. 159, 1612-1623 (1999). 